\title{
Liposomal Iron for Iron Deficiency Anemia in Women of Reproductive Age: Review of Current Evidence
}

\author{
Parag Biniwale1, Bhaskar Pal'2, Tripura Sundari ${ }^{3}$ Gorakh Mandrupkar4, \\ Nikhil Datar5, Amandeep Singh Khurana ${ }^{6}$, Amit Qamra6, Salman Motlekar6*, \\ Rishi Jain 6
}

\author{
${ }^{1}$ Department of Obstetrics \& Gynecology, Biniwale Clinic, Pune, India \\ ${ }^{2}$ Department of Obstetrics \& Gynecology, Apollo Gleneagles Hospital Ltd., Kolkata, India \\ ${ }^{3}$ Department of Obstetrics \& Gynecology, Krishna Institute of Medical Sciences, Secunderabad, India \\ ${ }^{4}$ Department of Obstetrics \& Gynecology, Mandrupkar Clinic, Islampur, India \\ ${ }^{5}$ Department of Obstetrics \& Gynecology, Cloudnine Hospital, Mumbai, India \\ ${ }^{6}$ Department of Medical Affairs, Wockhardt Limited, Mumbai, India \\ Email: parag.biniwale@gmail.com,palbas@hotmail.com,drsunda ri@gmail.com,drmango@rediffmail.com, \\ drnikhil70@hotmail.com, *smotlekar@wockhardt.com
}

How to cite this paper: Biniwale, P., Pal, B., Sundari, T., Mandrupkar, G., Datar, N., Khurana, A.S., Qamra, A., Motlekar, S. and Jain, R. (2018) Liposomal Iron for Iron Deficiency Anemia in Women of Reproductive Age: Review of Current Evidence. Open Journal of Obstetrics and Gynecology, 8, 993-1005.

https://doi.org/10.4236/ojog.2018.811100

Received: August 2, 2018

Accepted: September 8, 2018

Published: September 11, 2018

Copyright (c) 2018 by authors and Scientific Research Publishing Inc. This work is licensed under the Creative Commons Attribution International License (CC BY 4.0).

http://creativecommons.org/licenses/by/4.0/

\section{(c) (i) Open Access}

\begin{abstract}
Iron deficiency anemia is the most frequent nutritional deficiency disorder. Conventionally administered oral iron is associated with gastrointestinal intolerance that affects the outcomes and compliance. Liposomal iron is associated with increased absorption without causing significant adverse effects. In this review, we have discussed the technology of liposomal iron preparation, mechanisms of its absorption and clinical evidence on its utility in iron deficiency states in pregnant and non-pregnant women. Based on the available evidence, we compared liposomal iron to conventional oral iron. Encapsulation of micronized iron in liposomes is associated with lesser exposure to gastric contents, lesser interaction with food contents, no exposure to different digestive juices, targeted delivery of iron and allows lower doses to be administered in lieu of direct absorption without need for protein carriers. The available evidence suggests that liposomal iron significantly increases hemoglobin, ferritin levels in pregnant women as well as in women with iron deficiency.
\end{abstract}

\section{Keywords}

Liposomal Iron, Microencapsulated, Micronized, Iron Deficiency, Anemia, Pregnancy 


\section{Introduction}

Iron is absorbed almost completely from duodenum and performs multitude of physiological functions like erythropoiesis, oxidative metabolism, and cellular immune responses [1] [2]. Though iron is one of the most abundant elements on earth, iron deficiency is the most common nutritional disorder [3] [4]. World Health Organization (WHO) estimates that $29 \%$ of all women of reproductive age have anaemia globally [5]. In pregnancy, the nutritional demands are increased further. Among South-Asian countries, India has the highest burden of iron deficiency anemia [6]. A recent study from India reported 58.7\% prevalence of anemia in pregnancy [7]. Another study from north India in 3000 pregnant patients reported anemia in $86.6 \%$ pregnant females. Among these, $32.5 \%$, $60.30 \%$ and $7.20 \%$ had mild ( $\mathrm{Hb} 10-10.9 \mathrm{~g} / \mathrm{dl})$, moderate $(\mathrm{Hb} 7-9.9 \mathrm{~g} / \mathrm{dl})$ and severe anemia $(\mathrm{Hb}<7 \mathrm{~g} / \mathrm{dl})$ respectively [8].

Indian Council for Medical Research (ICMR) recommended daily allowance of iron is $35 \mathrm{mg} /$ day in pregnancy and $21 \mathrm{mg} /$ day in lactation [9]. Iron deficiency in pregnancy has harmful maternal and neonatal effects [10]. Conventionally, iron supplements are administered from second trimester of pregnancy [11]. However, a poor absorption of conventional iron limits its therapeutic efficacy. Further, unwanted adverse effect like gastrointestinal (GI) intolerance and food interactions hamper the compliance. Non-compliance to iron therapy is associated with increasing prevalence of anemia in later half of pregnancy [12].

Encapsulation of iron in a micronized form in to liposomes is the recent approach to improve iron tolerance and absorption. This new, promising strategy for delivering iron orally is associated with greater GI absorption, higher bioavailability with reduced incidence of adverse effects [13]. It is believed that because of no direct contact of iron with intestinal mucosa, it is better absorbed and tolerated [13]. Therefore, supplementing liposomal iron in pregnancy can be helpful to improve tolerability, compliance, and outcomes of the therapy. In this review, we discuss clinical evidence on use of liposomal iron in pregnancy and non-pregnant women of reproductive age, along with its mechanisms.

\section{Limitations of Conventional Oral Iron Therapy}

Iron salts like ferrous sulphate, ferrous fumarate, etc. are used in management of iron deficiency anemia. Iron from these salts is usually absorbed with help of various transporters like divalent metal transporter 1 (DMT-1) [4]. The major advantages of these oral iron salts are their extensive availability and low cost. However, conventional oral iron therapy is associated with a variety of limitations. GI intolerance (nausea, flatulence, abdominal pain, diarrhea, constipation, and black or tarry stools) is the most frequent adverse effect associated with oral iron. A meta-analysis from Tolkien et al involving 20 trials $(n=3168)$ observed that Iron Sulphate was associated with significantly greater risk of GI side effects compared to placebo (Odds ratio (OR) 2.32, $\mathrm{p}<0.0001$ ) and intravenous iron (OR 3.3.05, $\mathrm{p}<0.0001)$. Of 20 trials, $7(\mathrm{n}=1028)$ were involving pregnant 
women and in this subgroup also, significantly higher GI side effects were reported (OR 3.33, $\mathrm{p}=0.02$ ). Pooled estimates from different studies identified prevalence of constipation, nausea and diarrhea to be $12 \%, 11 \%$ and $8 \%$ respectively [14]. This leads to impaired compliance to therapy. In a study of pregnant women, it was reported that only half of women (49.7\%) used iron therapy during whole of the pregnancy. Anemia correlated significantly with non-compliance to oral iron with adjusted OR of 6.19 ( $\mathrm{p}<0.0001)$. It was estimated that non-compliance to oral iron may range from $27 \%$ to $75 \%$ [8]. Besides these, food interactions with phytates, tannins, etc. present in food hamper the absorption [15].

With conventional iron salts, longer duration is necessary for the rise of $1 \mathrm{gm}$ of hemoglobin $(\mathrm{Hb})$ concentration. In a study from North India after 60 days treatment, rise of $\mathrm{Hb}$ was nearly $1 \mathrm{gm} \%$ with different iron salts available commercially-ferrous sulphate $(0.93 \pm 0.27 \mathrm{gm} \%)$, ferrous fumarate $(1.06 \pm 0.28$ $\mathrm{gm} \%)$, ferrous ascorbate $(1.13 \pm 0.35 \mathrm{gm} \%)$, ferrous bisglycinate $(1.11 \pm 0.27$ gm\%), and sodium feredetate $(1.09 \pm 0.31 \mathrm{gm} \%)$ [16]. Further, daily or twice-daily supplementation of oral iron salts increase hepcidin expression for nearly 24 hours which results in lower absorption of iron the next day. A study in iron-depleted young women conducted by Moretti et al. observed that 24 hours after intake of $\geq 60 \mathrm{mg}$ of ferrous sulphate, serum hepcidin was increased and fractional iron absorption was decreased by $35 \%$ to $45 \%$ ( $\mathrm{p}<0.01$ for both). This could be managed by higher doses of iron. However, in the same study it was reported that a six-fold increase in iron dose ( 40 to $240 \mathrm{mg}$ ) resulted in only a threefold increase in iron absorbed (6.7 to $18.1 \mathrm{mg}$ ) [17]. In presence of such issues with existing iron therapy, liposomal iron treatment seems more logical way to improve iron deficiency state in pregnancy and non-pregnant women of reproductive age.

\section{Liposomal Iron}

Liposomes are one of the effective drug carrier systems which potentially deliver different therapeutic substances to specific molecular targets. Their biocompatibility, biodegradability and low toxicity make them suitable for delivering drugs. Iron delivery via liposomes is promising approach.

\subsection{Technological Details}

Micronization: It involves reduction in particle size which increases solubility of the iron. Processing in to smaller particles increases the surface area to drug ratio and thereby the dissolution rate of the drug (Figure 1). This results in increased bioavailability of poorly aqueous soluble drugs [18] [19]

Microencapsulation: The micronized iron is encapsulated by a lipid bilayer membrane like biological membranes, resulting in microencapsulation (Figure 1). The formed liposome thus has outer bilayer membrane and inner core containing the iron particles. Outer phospholipid bilayer provides advantages like 


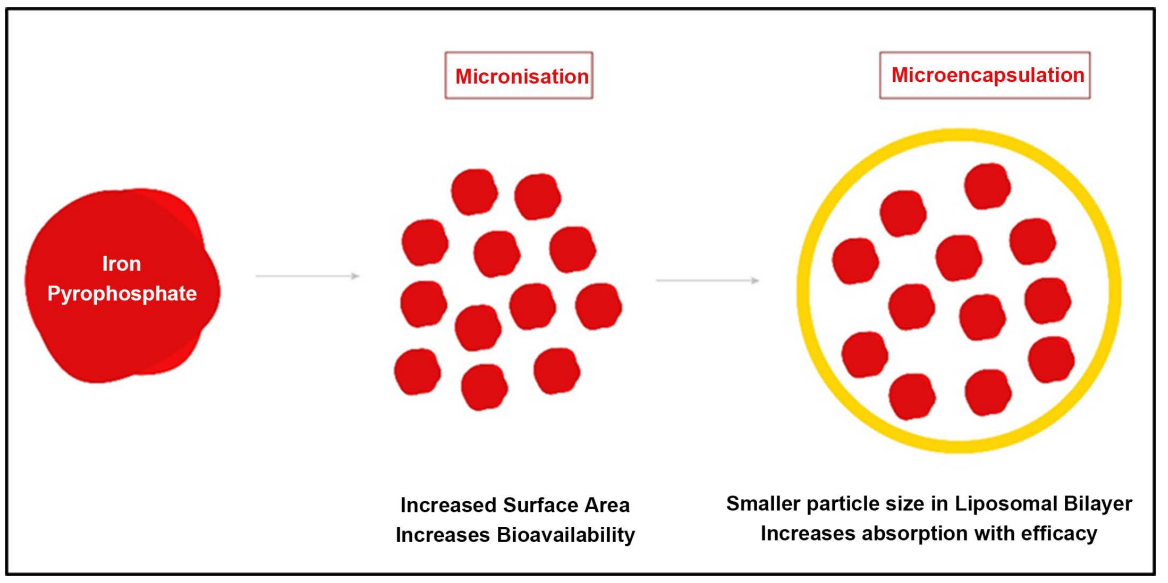

Figure 1. Schematic representation of micronization and microencapsulation [18] [19] [20].

resistance to degradation of iron from enzymes in mouth and/or stomach, interaction with alkaline juices, bile salts, intestinal flora and protection from free radicals. The protection offered from liposomes prevents oxidation and degradation of the iron contents in the core. This further assists in targeted delivery [20].

\subsection{Mechanism of Absorption}

As the composition of outer membrane of liposomal iron is similar to that of biological membranes, different mechanisms may be instrumental in absorption. The mechanisms of absorption are multiple and involve:

1) Simple adsorption which increases local concentration of liposomal contents at intestinal membrane with resultant absorption by diffusion or transporters;

2) Endocytosis with subsequent breakdown of liposomal membrane by intracellular lysosomes;

3) Fusion of lipid bilayer to plasma membrane with release of contents in to the cytoplasm;

4) Exchange of lipids between liposomal bilayer and plasma cell membrane causing liposomal bilayer instability with subsequent release of contents intracellularly [20].

Thus, liposomes iron delivery may avoid any protein mediated carrier transport of iron. This can ultimately result in better bioavailability of iron. Figure 2 schematically represents the mechanisms of liposomal iron absorption. Additionally, direct absorption via microfold cells ( $\mathrm{M}$ cells) in Peyer's patches bypassing the conventional routes of absorption may be involved in liposomal iron absorption as suggested in an in-vitro study [21]. However, it remains unclear to what extent each mechanism contributes to the overall absorption of iron. In experimental studies, administration of liposomal iron was reported to be associated with significant increase in red cell count, hematocrit, serum iron levels and liver iron levels [22] [23]. 


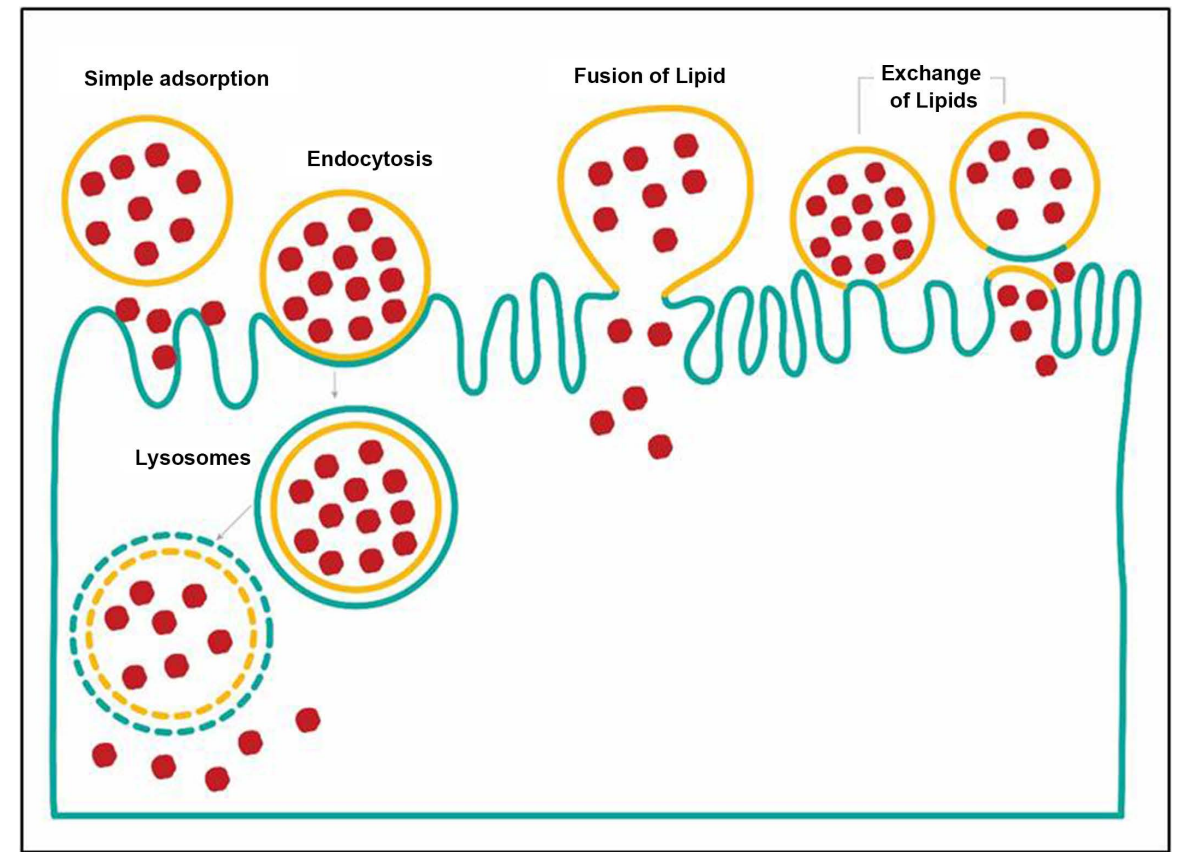

Figure 2. Schematic representation of liposomal iron absorption [20].

\subsection{Advantages with Liposomal Iron}

1) Quicker absorption and restoration of the iron content: Experimental evidence suggests liposomal iron recovers iron levels in liver quickly than conventional oral iron [23]. Multiple studies suggest that liposomal encapsulation of iron is associated with enhanced iron absorption compared to non-capsulated conventional oral iron [24] [25].

2) No induction of oxidative damage: Evidence suggests that liposomal iron is associated with decreased malondialdehyde levels and increase in super-oxide dismutase levels. This may help in minimizing the oxidative damage that is possibly induced by conventional iron [23].

3) Absorption with improved capacity: Compared to heme iron, it is better absorbed and has lower adverse side effects probably due to lower oxidative damage [23].

4) Physical stability and gradual release property: Liposomes are unilamellar vesicles and are nano-sized particles. Lipid bilayer provides stability and may release the contents gradually. Gradual release may help in better absorption of liposomal contents [22].

\section{Clinical Evidence in Non-Pregnant Iron Deficient Females}

In a randomized double-blind placebo-controlled 16-week trial, Blanco-Rojo et al. [26] randomized iron deficient women to fruit juice fortified with either microencapsulated iron pyrophosphate (F group, $\mathrm{n}=64$ ) or placebo (P group, $\mathrm{n}=$ 58) as a supplement to usual diet. Microencapsulated iron pyrophosphate provided $18 \mathrm{mg}$ iron per day. Assessment parameters included dietary intake, body weight, total erythrocytes, haematocrit, mean corpuscular volume (MCV), red 
blood cell distribution width (RDW), Hb, serum Fe, serum ferritin, serum transferrin, transferrin saturation, soluble transferrin receptor (sTfR) and zinc protoporphyrin ( $\mathrm{ZnPP})$ and were evaluated at baseline and monthly till 16 weeks. The improvement in total erythrocyte count $(p=0.046)$, hematocrit $(p=$ $0.006), \mathrm{RDW}(\mathrm{p}=0.003), \mathrm{Hb}(\mathrm{p}<0.0001)$, serum ferritin $(\mathrm{p}<0.0001)$ and $\mathrm{sTfR}$ $(\mathrm{p}=0.01)$ were significant compared to placebo. Figure 3 shows the changes in $\mathrm{Hb}$ and ferritin levels in two groups. This study finding suggested that fortification of fruit juice with microencapsulated iron can be useful for prevention of iron deficiency anemia in high-risk population.

In another study, Pleşea-Condratovici et al. evaluated 30 post-menopausal females aged 45 - 65 years who had presented with iron deficiency anemia $(\mathrm{Hb}<$ $11.5 \mathrm{~g} / \mathrm{dl}$ ). Among patients included, some had already been treated with other iron supplements or drugs experiencing side effects except allergy. After eight weeks of liposomal iron supplementation (microencapsulated iron pyrophosphate in liposomal form), mean level of $\mathrm{Hb}$ increased from $10.65 \pm 0.35 \mathrm{mg} / \mathrm{dL}$ at baseline to $12.77 \pm 0.70$ at the end of the study $(\mathrm{P}<0.0001)$ (Figure 4$)$. There was also significant rise in hematocrit levels from a mean of $33.32 \% \pm 2.78 \%$ at baseline to $38.95 \% \pm 2.92 \%$ at end of the study $(\mathrm{P}<0.0001)$. Liposomal iron supplement was well tolerated with statistically significant improvement of all side effects previously experienced by the patients. The only and minor effect reported was stool coloring [27]. Thus, microencapsulated iron in liposomal form improves iron absorption leading to high bioavailability. Increase in hemoglobin is quick and is devoid of side effects like stomach upset and constipation which are associated with the high-dose conventional oral iron.

\section{Clinical Evidence in Pregnant Females}

Parisi et al. [28] in a randomized trial evaluated effect of different doses of liposomal iron in comparison to ferrous sulphate. They enrolled 80 non-anemic pregnant women in 12 to 14 weeks of gestation and were randomized to one of the four treatments as-

- Group 1: FF14 (liposomal iron $14 \mathrm{mg} / \mathrm{d}$ )

- Group 2: FF28 (liposomal iron $28 \mathrm{mg} / \mathrm{d}$ )

- Group 3: SF (ferrous sulphate $30 \mathrm{mg} / \mathrm{d}$ )

- Group 4: C (control without any supplement).

Data like hemoglobin, ferritin, transferrin, iron levels from these patients were evaluated at baseline, 20 weeks, 28 weeks and at 6 weeks postpartum. Results obtained in this study are discussed under following headings.

a) Change in hemoglobin levels

FF28 showed significant increase compared to SF $(\mathrm{p}<0.01)$ and $\mathrm{C}(\mathrm{p}<0.05)$ groups at 28 weeks and in post-partum period.

b) Changes in ferritin levels

Compared to control, FF28 treatment was associated with significantly higher ferritin levels at 20 weeks $(\mathrm{p}=0.05), 28$ weeks $(\mathrm{p}<0.01)$ and in post-partum pe$\operatorname{riod}(\mathrm{p}<0.01)$. 


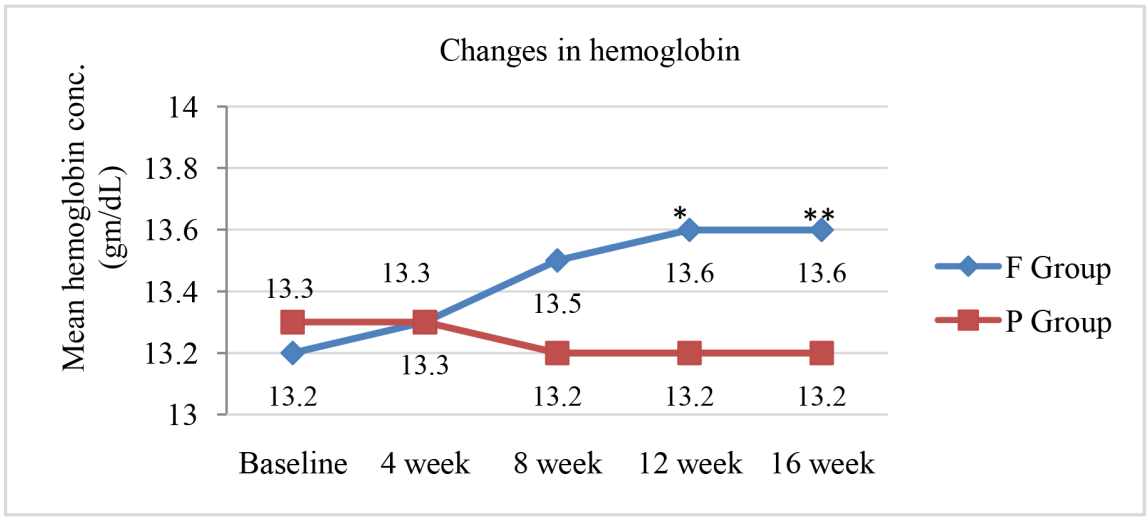

(a)

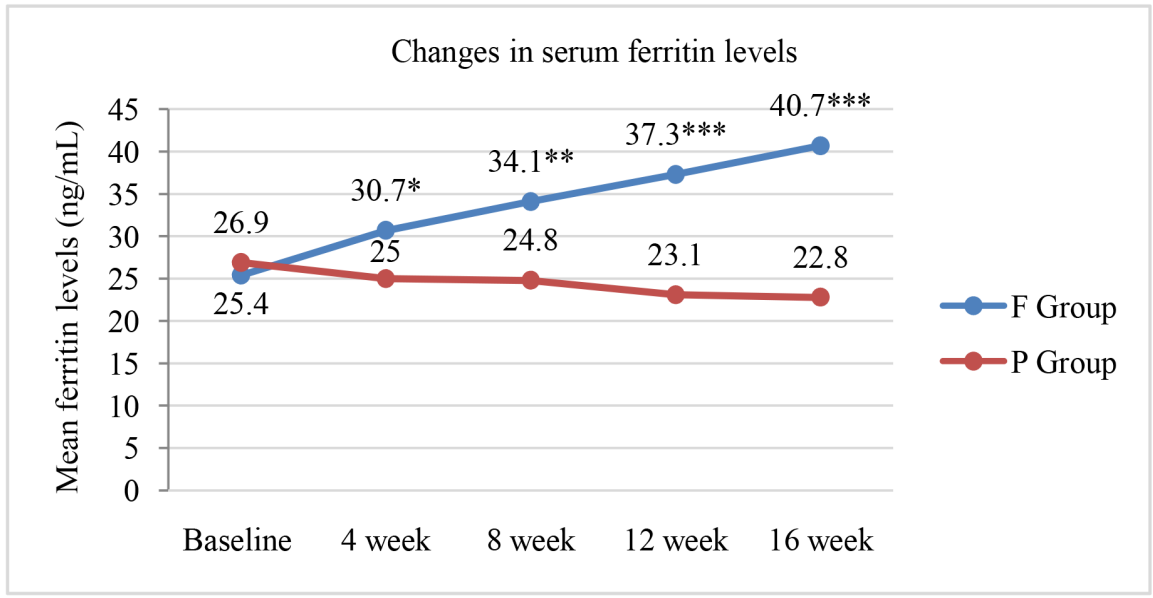

(b)

Figure 3. Changes in hemoglobin (a) and ferritin (b) levels over 16 weeks in two groups. (a) ${ }^{\star} \mathrm{p}<0.05,{ }^{* *} \mathrm{P}<0.001$ compared to placebo; $\mathrm{F}$ group: iron pyrophosphate, $\mathrm{P}$ group: Placebo; (b) ${ }^{\star} \mathrm{p} \leq 0.05,{ }^{* *} \mathrm{P} \leq 0.001,{ }^{* * *} \mathrm{p} \leq 0.0001$ compared to placebo; F group: iron pyrophosphate, $\mathrm{P}$ group: Placebo.

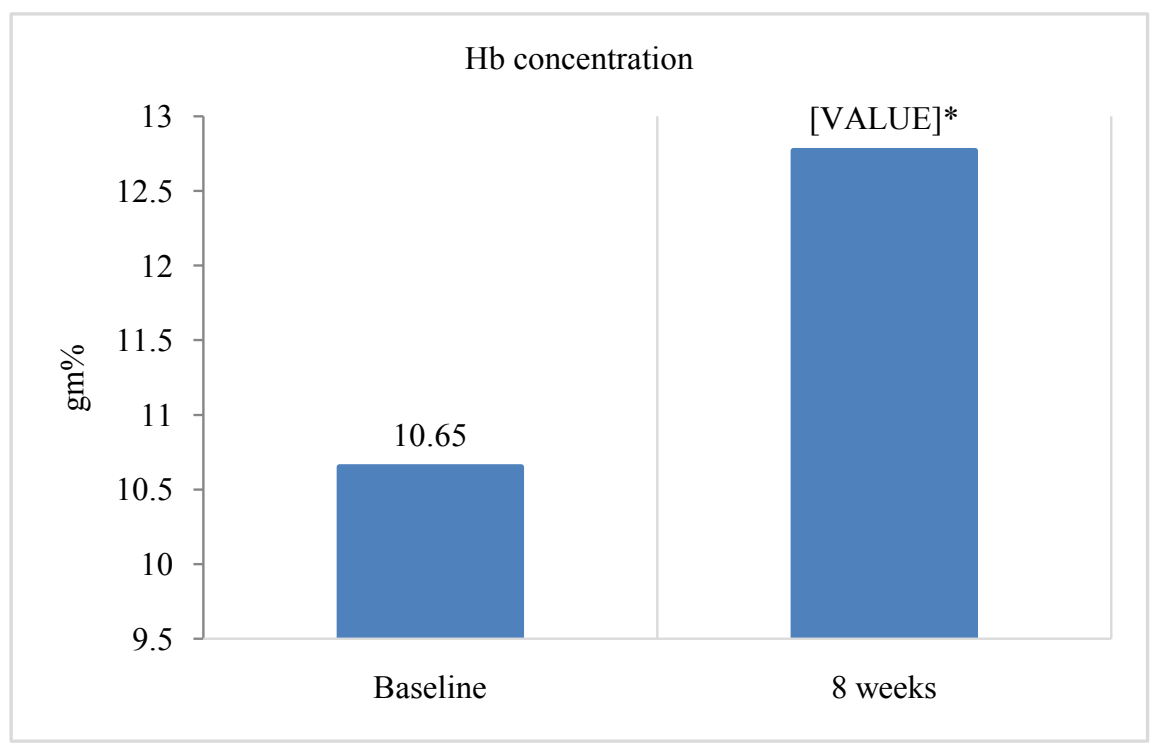

Figure 4. Change in serum $\mathrm{Hb}$ concentration form baseline to 8 weeks. ${ }^{\star} \mathrm{P}<0.0001$. 


\section{c) Drop out for anemia}

Numerically, drop-outs were higher in control $(\mathrm{n}=6), \mathrm{SF}$ and FF14 $(\mathrm{n}=5$ each) than FF28 ( $\mathrm{n}=2)$.

d) Pregnancy outcomes

There were no differences in placental weight, blood loss, and gestational age at delivery among the four groups. Compared to control, birth weight was significantly higher in FF28 group (3479 \pm 587 gm vs $3092 \pm 469$ gm, p $<0.05)$.

Thus, the results suggest that $28 \mathrm{mg}$ of liposomal iron is associated with significant improvement in $\mathrm{Hb}$ and ferritin levels which may prevent maternal anemia and improves birth weight. Changes in hematological parameters seen with $30 \mathrm{mg}$ of ferrous sulphate were equivalent to that seen with $14 \mathrm{mg}$ of liposomal iron. This suggests use of liposomal iron allows use of lower doses and thereby may help in ameliorating the adverse effects.

In another similar trial, Parisi et al. [29] randomized a cohort of 55 first trimester pregnant anemic $(\mathrm{Hb}<10.5 \mathrm{gm} / \mathrm{dL})$ women to one of the treatments as-

- Group 1: Fe sulphate $30 \mathrm{mg}(\mathrm{FeS} 30, \mathrm{n}=13)$

- Group 2: Liposomal ferric pyrophosphate $14 \mathrm{mg}(\mathrm{FeP} 14, \mathrm{n}=12)$

- Group 3: Liposomal ferric pyrophosphate $28 \mathrm{mg}(\mathrm{FeP}, 28, \mathrm{n}=11)$

- Group 4: Control group with no supplementation (C, $n=19)$.

Various hematological parameters were assessed at the time of enrolment, at 28 weeks and the outcomes of pregnancy were noted after delivery.

- Change in Hb levels. At week 28 of gestation irrespective of food intake, FeP28 treatment was associated with significantly greater increase in $\mathrm{Hb}$ compared to control $(\mathrm{p}<0.01)$ with no significant differences among other groups. From control, FeS and Fep14 group 5, 2 and 1 women respectively developed sideropenic anemia but none was noted from FeP 28 group.

- Food frequency questionnaire (FFQ): Compared to other groups, control group had consumed more amounts of naturally bioavailable iron i.e. meat.

- Pregnancy outcomes. There were no significant differences in four groups.

- Thus, the results point out that liposomal iron supplementation is associated with better protection in anemia than conventional ferrous sulphate at lower dosage. Table 1 summarizes the current evidence with liposomal iron.

\section{Comparison of Liposomal Iron to Conventional Iron}

Based on this current evidence, potential differences between liposomal iron and conventional oral iron are summarized in Table 2.

\section{Safety of Ferric Pyrophosphate}

Ferric pyrophosphate is the usual form of iron used for liposomal iron delivery. The United States Food and Drugs Administration (USFDA) Code of Federal Regulations states that ferric pyrophosphate is generally recognized as safe (GRAS) when used in accordance with good manufacturing or feeding practice. European Food Safety Authority (EFSA) also suggests that ferric pyrophosphate 
Table 1. Clinical evidence with liposomal iron.

\begin{tabular}{|c|c|c|c|c|}
\hline \multirow[b]{2}{*}{ Author (year) } & \multicolumn{3}{|c|}{ Study details } & \multirow[b]{2}{*}{ Major findings } \\
\hline & Design and subjects & Interventions & $\begin{array}{l}\text { Assessment } \\
\text { timeframes }\end{array}$ & \\
\hline \multicolumn{5}{|c|}{ Non-pregnant women } \\
\hline $\begin{array}{l}\text { Blanco-Rojo et al. } \\
\text { (2011) [26] }\end{array}$ & $\begin{array}{l}\mathrm{RCT} \\
\mathrm{N}=122 \\
18-35 \text { years } \\
\text { Low Fe stores } \\
\text { (serum ferritin }<40 \mathrm{ng} / \mathrm{ml} \text { ) } \\
\mathrm{Hb} \geq 110 \mathrm{~g} / \mathrm{l}\end{array}$ & $\begin{array}{l}\text { microencapsulated iron } \\
\text { pyrophosphate (F group, } \mathrm{n}= \\
64) \text { Vs placebo (P group, } \mathrm{n}= \\
\text { 58) as supplement to diet }\end{array}$ & 16 weeks & 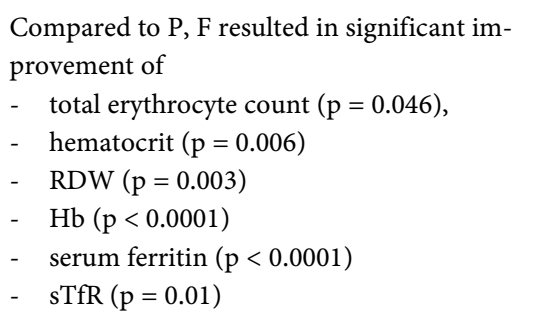 \\
\hline $\begin{array}{l}\text { Pleşea-Condratovici } \\
\text { et al. (2012) [27] }\end{array}$ & $\begin{array}{l}\text { Open label } \\
\mathrm{N}=30 \\
\text { Post-menopausal } \\
45-65 \text { years } \\
\mathrm{Hb}<11.5 \mathrm{gm} / \mathrm{dL} \\
\text { Previous side effects with } \\
\text { iron supplements } \\
\text { Intervention: }\end{array}$ & $\begin{array}{l}\text { microencapsulated iron } \\
\text { pyrophosphate in liposomal } \\
\text { form }\end{array}$ & 8 weeks & $\begin{array}{l}\text { Liposomal iron supplementation was associ- } \\
\text { ated with significant increase in } \\
\text { - } \text { Hb levels }(\mathrm{p}<0.0001) \\
\text { - } \text { Hematocrit levels }(\mathrm{P}<0.0001) \\
\text { - } \\
\text { - } \\
\text { no dropouts } \\
\text { well tolerated: significant improvement } \\
\text { previously experienced by the patients }\end{array}$ \\
\hline \multicolumn{5}{|c|}{ Pregnant women } \\
\hline $\begin{array}{c}\text { Parisi et al. (2012) } \\
\text { [28] }\end{array}$ & $\begin{array}{l}\mathrm{RCT} \\
\mathrm{N}=80 \\
\text { Non-anemic }\end{array}$ & $\begin{array}{l}\text { Group 1: FF14: Liposomal iron } \\
14 \mathrm{mg} / \mathrm{d} \\
\text { Group 2: FF28: Liposomal iron } \\
28 \mathrm{mg} / \mathrm{d} \\
\text { Group 3: SF: ferrous sulphate } \\
30 \mathrm{mg} / \mathrm{d} \\
\text { Group 4: C: control }\end{array}$ & $\begin{array}{l}\text { At } 20 \text { weeks, } \\
28 \text { weeks and } \\
6 \text { weeks } \\
\text { post-partum }\end{array}$ & $\begin{array}{l}\text { FF28 was associated with } \\
\text { - } \text { significant improvement of } \mathrm{Hb}(\mathrm{p}<0.01 \mathrm{vs} \\
\mathrm{SF} \text { and }<0.05 \text { vs } \mathrm{C}) \text { at } 28 \text { weeks and in } \\
\text { post-partum period } \\
\text { - } \quad \text { significant improvement of ferritin levels } \\
\text { than control at } 20 \text { weeks }(\mathrm{p}=0.05), 28 \\
\text { weeks }(\mathrm{p}<0.01) \text { and in post-partum } \\
\text { period }(\mathrm{p}<0.01) \\
\text { - lower drop outs }(\mathrm{n}=2) \text { than } \mathrm{SF}(\mathrm{n}=5) \\
\text { and } \mathrm{C}(\mathrm{n}=6) \\
\text { - } \begin{array}{l}\text { significantly higher birth weight } \\
(\mathrm{p}<0.05 \mathrm{vs} \mathrm{C})\end{array}\end{array}$ \\
\hline $\begin{array}{c}\text { Parisi et al. (2012) } \\
{[29]}\end{array}$ & $\begin{array}{l}\text { RCT } \\
\mathrm{N}=55 \\
\text { Anemic }(\mathrm{Hb}<10.5 \text { gm } \%)\end{array}$ & $\begin{array}{l}\text { Group 1: Fe sulphate } 30 \mathrm{mg} \\
\text { (FeS 30, } \mathrm{n}=13 \text { ) } \\
\text { Group 2: Liposomal ferric } \\
\text { pyrophosphate } 14 \mathrm{mg} \\
\text { (FeP 14, } \mathrm{n}=12 \text { ) } \\
\text { Group 3: Liposomal ferric } \\
\text { pyrophosphate } 28 \mathrm{mg} \\
\text { (FeP, 28, } \mathrm{n}=11 \text { ) } \\
\text { Group 4: control group with } \\
\text { no supplementation } \\
(\mathrm{C}, \mathrm{n}=19)\end{array}$ & $\begin{array}{l}\text { At } 28 \text { weeks, } \\
\text { After delivery }\end{array}$ & $\begin{array}{l}\text { FeP28 treatment was associated } \\
\text { - } \text { significantly greater increase in } \mathrm{Hb} \\
\text { compared to control }(\mathrm{p}<0.01) \text { at } 28 \\
\text { weeks (with no other group having } \\
\text { significant difference compared to control) } \\
\text { - no development of siderophenic anemia } \\
\text { compared to women in control }(\mathrm{n}=5), \\
\text { FeS }(\mathrm{n}=2) \text { and FeP14 }(\mathrm{n}=1) \text { groups }\end{array}$ \\
\hline
\end{tabular}

is safe for use as food additive. Additionally, current clinical evidence discussed above suggests that there are no major untoward effects in pregnant and non-pregnant women. Thus, ferric pyrophosphate in liposomal iron delivery is safe for treatment of iron deficiency. 
Table 2. Differences between liposomal iron and conventional oral iron.

\begin{tabular}{ccc}
\hline Characteristic & Liposomal iron & Conventional Iron \\
\hline Phospholipid Bilayer & Present & Absent \\
Effect of gastric acidity & None & Present \\
Oxidation of iron & No & Yes \\
Targeted iron delivery & Yes & No \\
Absorption of iron & Enhanced & Regular \\
Absorption via intestinal M cells & Yes & No \\
Food effect & No & Yes \\
Oxidative damage to intestinal epithelium & No & Yes \\
Gastrointestinal side effects & Minimal/Absent & Yes \\
Metallic taste & No & Yes \\
Chelation with other metals & No & Yes
\end{tabular}

\section{Future Research Perspective}

As liposomal iron becomes commercially available, its effectiveness in larger population will become clear. Future clinical studies should compare liposomal iron with different commercially available iron salts to determine its comparative utility. Also, its use in pregnancy may be encouraged to increase compliance to oraliron therapy as available iron salts pose problems of GI intolerance in majority of the patients. Studies are required to compare its utility in different grades of iron deficiency anemia to ascertain its role in severe iron deficiency anemia as well. A comparative evaluation to parenteral iron treatment will tell us its utility in severe iron deficiency anemia and might prove to be an alternate option to parenteral iron as well, if proven effective.

\section{Conclusion}

Conventional iron therapy is associated with gastrointestinal intolerance, constipation and food intolerance which hampers compliance to therapy. Improving compliance to oral iron is one of the essential component. Micronization of iron and encapsulation of the micronized iron in liposomes has provided newer opportunities for improving tolerance with oral iron therapy. Liposomes have been used since long as carriers for drugs. Liposomal carriage of iron is associated with lesser exposure to gastric contents, lesser interaction with food contents, no exposure to different digestive juices, is associated with targeted delivery of iron and allows lower doses to be administered because of direct absorption in to the blood stream without need for protein carriers. Liposomal iron significantly increases hemoglobin, ferritin levels in pregnant women as well as in women with iron deficiency as suggested from clinical evidence. Use of lower doses of liposomal iron was effective in comparison to usual doses of ferrous sulphate. This is helpful in reducing GI adverse effects associated with non-capsulated conven- 
tional oral iron. The safety of ferric pyrophosphate is suggested from its recognition as GRAS by the USFDA and as food additive by EFSA.

\section{Acknowledgements}

Authors thank and acknowledge Dr. Vijay M Katekhaye (Quest MedPharma Consultants, Nagpur, India) for his assistance in drafting the manuscript.

\section{Conflicts of Interest}

Amandeep Singh Khurana, Amit Qamra, Salman Motlekar, and Rishi Jain are salaried employees of Wockhardt Ltd., Mumbai, India. Other authors declare no conflicts of interests.

\section{References}

[1] Muñoz, M., Villar, I., García-Erce, J.A. (2009) An Update on Iron Physiology. World Journal of Gastroenterology, 15, 4617-4626. https://doi.org/10.3748/wjg.15.4617

[2] Waldvogel-abramowski, S., Waeber, G., Gassner, C., Buser, A., Frey, B.M., Favrat, B., et al. (2014) Physiology of Iron Metabolism. Transfusion Medicine and Hemotherapy, 41, 213-221. https://doi.org/10.1159/000362888

[3] Coad, J. and Conlon, C. (2011) Iron Deficiency in Women: Assessment, Causes and Consequences. Current Opinion in Clinical Nutrition and Metabolic Care, 14, 625-634. https://doi.org/10.1097/MCO.0b013e32834be6fd

[4] Abbaspour, N., Hurrell, R. and Kelishadi, R. (2014) Review on Iron and Its Importance for Human Health. Journal of Research in Medical Sciences, 19, 164-174.

[5] World Health Organization (WHO) (2015) The Global Prevalence of Anemia in 2011. World Health Organization, Geneva. http://apps.who.int/iris/handle/10665/177094

[6] Kalaivani, K. (2009) Prevalence \& Consequences of Anaemia in Pregnancy. Indian Journal of Medical Research, 130, 627-633.

[7] Siddiqui, M.Z., Goli, S., Reja, T., Doshi, R., Chakravorty, S., Tiwari, C., et al. (2017) Prevalence of Anemia and Its Determinants among Pregnant, Lactating, and Nonpregnant Nonlactating Women in India. SAGE Open, 7, 1-10.

[8] Tyagi, N., Kaushik, A., Khatri, A. and Ranga, S. (2016) Prevalence of Type and Severity of Anemia in Antenatal Cases in a Tertiary Care Hospital in North India. Annals of Woman and Child Health, 2, A6-A10.

[9] Indian Council for Medical Research, Dietary Guidelines for Indians-A Manual. (2011) National Institute of Nutrition, Hyderabad, India. 2nd Edition, p. 89. http://ninindia.org/dietaryguidelinesforninwebsite.pdf

[10] Gautam, C.S., Saha, L., Sekhri, K. and Saha, P.K. (2008) Iron Deficiency in Pregnancy and the Rationality of Iron Supplements Prescribed During Pregnancy. Medscape Journal of Medicine, 10, 283.

[11] Federation of Obstetric \& Gynecological Societies of India (2011) Good Clinical Practice Recommendations for Iron Deficiency Anemia in Pregnancy (IDA) in Pregnancy in India. The Journal of Obstetrics and Gynecology of India, 61, 569-571. https://doi.org/10.1007/s13224-011-0097-5

[12] Habib, F., Alabdin, E.H.Z., Alenazy, M. and Nooh, R. (2009) Compliance to Iron 
Supplementation during Pregnancy. Journal of Obstetrics and Gynaecology, 29, 487-492. https://doi.org/10.1080/01443610902984961

[13] Pisani, A., Riccio, E., Sabbatini, M., Andreucci, M., Del Rio, A. and Visciano, B. (2014) Effect of Oral Liposomal Iron versus Intravenous Iron for Treatment of Iron Deficiency Anaemia in CKD Patients: A Randomized Trial. Nephrology Dialysis Transplantation, 30, 645-652. https://doi.org/10.1093/ndt/gfu357

[14] Tolkien, Z., Stecher, L., Mander, A.P., Pereira, D.I.A. and Powell, J.J. (2015) Ferrous Sulfate Supplementation Causes Significant Gastrointestinal Side-Effects in Adults: A Systematic Review and Meta-Analysis. PLoS ONE, 10, e0117383. https://doi.org/10.1371/journal.pone.0117383

[15] Nair, K.M. and Iyengar, V. (2009) Iron Content, Bioavailability and Factors Affecting Iron Status of Indians. Indian Journal of Medical Research, 130, 634-645.

[16] Singhal, S.R., Kadian, V., Singh, S. and Ghalaut, V.S. (2015) Comparison of Various Oral Iron Salts in the Treatment of Iron Deficiency Anemia in Pregnancy. Indian Journal of Obstetrics and Gynecology Research, 2, 155-158. https://doi.org/10.5958/2394-2754.2015.00005.3

[17] Moretti, D., Goede, J.S., Zeder, C., Jiskra, M., Chatzinakou, V., Tjalsma, H., et al. (2015) Oral Iron Supplements Increase Hepcidin and Decrease Iron Absorption from Daily or Twice Daily Doses in Iron Depleted Young Women. Blood, 126, 1981-1989. https://doi.org/10.1182/blood-2015-05-642223

[18] Radhika, M.S., Nair, K.M., Kumar, R.H., Rao, M.V., Ravinder, P., Reddy, C.G., et al. (2011) Micronized Ferric Pyrophosphate Supplied through Extruded Rice Kernels Improves Body Iron Stores in Children: A Double-Blind, Randomized, Placebo-Controlled Midday Meal Feeding Trial in Indian School Children. The American Journal of Clinical Nutrition, 94, 1202-1210. https://doi.org/10.3945/ajen.110.007179

[19] Moretti, D., Zimmermann, M.B., Wegmuller, R., Walczyk, T., Zeder, C. and Hurrel, R.F. (2006) Iron Status and Food Matrix Strongly Affect the Relative Bioavailability of Ferric Pyrophosphate in Humans. The American Journal of Clinical Nutrition, 83, 632-638. https://doi.org/10.1093/ajcn.83.3.632

[20] Akbarzadeh, A., Rezaei-Sadabady, R., Davaran, S., Joo, S.W., Zarghami, N., Hanifehpour, Y., et al. (2013) Liposome: Classification, Preparation, and Applications. Nanoscale Research Letters, 8, 102. https://doi.org/10.1186/1556-276X-8-102

[21] Brilli, E., Lipinski, P., Barnadas, R., Camacho, M., Fabino, A., Giordano, G., et al. (2017) Sucrosomial Iron Absorption Involve M Cells Interaction. Abstract No. 2217. 59th Annual Meeting and Exposition, American Society of Hematology. http://www.bloodjournal.org/content/130/Suppl_1/2217? sso-checked=true

[22] Yu, P.P., Chang, Y.Z. and Yu, P. (2015) Iron Liposome: A More Effective Iron Supplement for Sports Anemia and Anemia of Inflammation. Journal of Pharmaceutical Care \& Health Systems, 84, 1-3. https://doi.org/10.4172/2376-0419.S4-002

[23] Xu, Z., Liu, S., Wang, H., Gao, G., Yu, P. and Chang, Y. (2014) Encapsulation of Iron in Liposomes Significantly Improved the Efficiency of Iron Supplementation in Strenuously Exercised Rats. Biological Trace Element Research, 162, 181-188. https://doi.org/10.1007/s12011-014-0143-0

[24] Yuan, L., Geng, L., Ge, L., Yu, P., Duan, X., Chen, J., et al. (2013) Effect of Iron Liposomes on Anemia of Inflammation. International Journal of Pharmaceutics, 454, 82-89. https://doi.org/10.1016/j.ijpharm.2013.06.078

[25] Dutta, A.J., Patel, P. and Bansal, R.K. (2014) Compliance to Iron Supplementation among Pregnant Women: A Cross Sectional Study in Urban Slum. National Journal 
of Community Medicine, 5, 457-462.

[26] Blanco-Rojo, R., Perez-Granados, A.M., Toxqui, L., Delgado, M.A. and Vaquero, M.P. (2011) Efficacy of a Microencapsulated Iron Pyrophosphate-Fortified Fruit Juice: A Randomised, Double-Blind, Placebo-Controlled Study in Spanish Iron-Deficient Women. British Journal of Nutrition, 105, 1652-1659. https://doi.org/10.1017/S0007114510005490

[27] Pleşea-Condratovici, A., Pleşea-Condratovici, C., Rosoga, N. and Nedelcu, S. (2015) Efficacy and Tolerability of a Novel Food Supplement (Turbofer ${ }^{\circledR}$ ) Containing Microencapsulated Iron in Liposomal Form, in Female Iron Deficiency Anemia. Progress in Nutrition, 17, 214-219.

http://mattioli1885journals.com/index.php/progressinnutrition/article/view/4869

[28] Parisi, F., Fusè, F., Brunetti, M., Mazzocco, M., Berti, C. and Cetin, I. (2017) Effects of Different Regimens of Iron Supplementation on Iron Status and Pregnancy Outcomes in a Cohort of Healthy Pregnant Women: A Randomized Control Trial. The Journal of Maternal-Fetal \& Neonatal Medicine, 30, 1787-1792. https://doi.org/10.1080/14767058.2016.1224841

[29] Parisi, F., Brunetti, M., Fusè, F., Capriata, I., Mandò, C., Berti, C., et al. (2012) Relationship between Food Intake, Iron Supplementation, Haematochemical State and Outcomes in Pregnancy, in a Cohort of Pregnant Women in Italy. Woman-The Fascination of Modern Gynecology between Health and Woman Security: Upgrades and Necessities, Congress Palace, Montecatini Terme, Italy, 12-14 April 2012.

\section{Abbreviation List}

EFSA: European Food Safety Authority

Fe: Iron

FeS: Ferrous sulphate

FeP: Ferrous pyrophosphate

FFQ: Food frequency questionnaire

GI: Gastrointestinal

GRAS: Generally recognized as safe

Hb: Haemoglobin

ICMR: Indian Council for Medical Research

MCV: Mean corpuscular volume

OR: Odds ratio

RDW: Red blood cell distribution width

sTfR: Soluble transferrin receptor

USFDA: United States Food and Drugs Administration

WHO: World Health Organization

ZnPP: Zinc protoporphyrin 